\title{
Experimental and Numerical Performance Analysis of a Self-Starting Three-Dimensional Scramjet Intake
}

\author{
Andreas K. Flock* and Ali Gülhan \\ DLR, German Aerospace Center, 51147 Cologne, Germany
}

DOI: $\underline{10.2514 / 1 . B 36602}$

\begin{abstract}
In this work, a three-dimensional intake model was investigated in a blowdown wind tunnel and results were compared and complemented with Reynolds-averaged Navier-Stokes simulations. The intake model was equipped with a movable cowl with which the internal contraction ratio was set to the self-starting limit. Three different conditions were investigated: first, a v-shaped cowl geometry at a freestream Mach number of seven; second, a straight cowl geometry at a freestream Mach number of seven; and, finally, a v-shaped cowl geometry at a freestream Mach number of six. Furthermore, a one-dimensional postanalysis was performed to calculate overall engine parameters from stream-thrust-averaged intake performance parameters. Numerical results were within the experimental uncertainty, except for small displacements near separation regions. The mass capture ratio of the $v$-shaped cowl was slightly higher as compared to the straight cowl. When increasing the Mach number from six to seven, the specific impulse dropped from 2561 to 2100 s, respectively. For the Mach 7 configurations, a maximum sustainable backpressure ratio of approximately 115 was measured. For the Mach 6 case, the maximum sustainable static backpressure ratio dropped to about 85 . The maximum sustainable backpressure to operating backpressure ratio was around 4:1, and it was independent of the Mach number.
\end{abstract}

\section{Nomenclature}

$A \quad=$ area, $\mathrm{m}^{2}$

$c_{f} \quad=$ skin-friction coefficient

$c_{p}=$ specific heat at constant pressure, $\mathrm{J} / \mathrm{kg} / \mathrm{K}$

$D \quad=$ diameter, $\mathrm{m}$

$E \quad=\quad$ total energy, $\mathrm{J} / \mathrm{kg}$

$e \quad=\quad$ internal energy, $\mathrm{J} / \mathrm{kg}$

$F \quad=$ (specific) thrust, $\mathrm{Ns} / \mathrm{kg}$

$h \quad=$ specific enthalpy, $\mathrm{J} / \mathrm{kg}$

$I=$ impulse, $\mathrm{s}$

$M \quad=$ Mach number

$m \quad=$ mass ratio

$\dot{m}=$ mass flow rate, $\mathrm{kg} / \mathrm{s}$

$\mathrm{Pr} \quad=$ Prandtl number

$p \quad=$ pressure, $\mathrm{N} / \mathrm{m}^{2}$

$q=$ dynamic pressure, $\mathrm{N} / \mathrm{m}^{2}$

$q=$ heat flux, $\mathrm{W} / \mathrm{m}^{2}$

$R=$ specific gas constant, $\mathrm{J} / \mathrm{kg} / \mathrm{K}$

$r \quad=$ radius, $\mathrm{m}$

$\mathrm{Su}=$ Sutherland constant, $\mathrm{K}$

$T=$ temperature, $\mathrm{K}$

$v \quad=$ velocity, $\mathrm{m} / \mathrm{s}$

$x, y, z=$ spatial coordinates, $\mathrm{m}$

$y+\quad=$ nondimensional wall distance

$\alpha=$ angle of attack, deg

$\gamma \quad=\quad$ ratio of specific heats

$\varepsilon \quad=$ sweep angle, deg

$\eta \quad=$ efficiency

$\Theta=$ temperature ratio

Presented as Paper 2015-3680 at the 20th AIAA International Space Planes and Hypersonic Systems and Technologies Conference, Glasgow, Scotland, 6-9 July 2015; received 9 January 2017; revision received 14 February 2017; accepted for publication 25 April 2017; published online Open Access 14 July 2017. Copyright $\odot 2017$ by Andreas K. Flock. Published by the American Institute of Aeronautics and Astronautics, Inc., with permission. All requests for copying and permission to reprint should be submitted to CCC at www.copyright.com; employ the ISSN 0748-4658 (print) or 1533-3876 (online) to initiate your request. See also AIAA Rights and Permissions www.aiaa.org/randp.

*Research Scientist, Supersonic and Hypersonic Technologies Department, Institute of Aerodynamics and Flow Technology, Linder Höhe; andreas.flock@ dlr.de.

†Department Head, Supersonic and Hypersonic Technologies Department, Institute of Aerodynamics and Flow Technology, Linder Höhe.

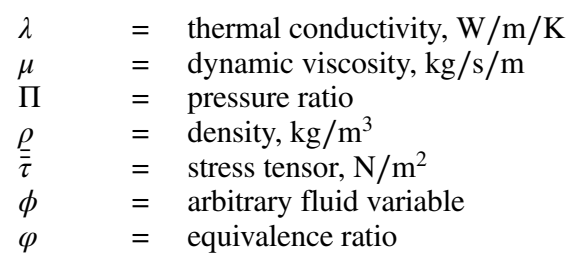

Subscripts

$\begin{array}{ll}\mathrm{cc} & =\text { combustion chamber } \\ \mathrm{cl} & =\text { cowl closure } \\ H & =\text { hydraulic } \\ i & =\text { internal portion } \\ \mathrm{KE} & =\text { kinetic energy } \\ \mathrm{max} & =\text { maximum } \\ o & =\text { overall portion } \\ \mathrm{oa} & =\text { overall } \\ \mathrm{Q} 3 & =\mathrm{Q} 3 \text { position } \\ \mathrm{Q} 4 & =\mathrm{Q} 4 \text { position } \\ \mathrm{sp} & =\text { specific } \\ \mathrm{st} & =\text { static } \\ \mathrm{stoi} & =\text { stoichiometric } \\ t & =\text { total } \\ w & =\text { wall } \\ \infty & =\text { freestream condition }\end{array}$

\section{Introduction}

$\mathbf{H}$ YPERSONIC flight within Earth's atmosphere offers advantages for military as well as civil applications. In altitudes up to $40 \mathrm{~km}$, airbreathing engines usually have better efficiency than rocket engines because air from the surrounding atmosphere is used as oxidizer. One airbreathing engine cycle, suitable for hypersonic flight, is the supersonic combustion ramjet (or scramjet). In a scramjet engine, air is compressed in the intake and passes through a short isolator section into the combustion chamber. In the combustion chamber, fuel is injected, mixed, and burned with the airstream; finally, the exhaust is accelerated through a nozzle.

In this work, we focus on the intake, which compresses the airflow to conditions suitable for supersonic combustion. For robust hydrogen combustion, a static pressure of $50,000 \mathrm{~Pa}$ is regarded as sufficient, whereas the static pressure mainly influences the combustion length ([1] p. 96). Ignition is frequently achieved through local hot spots [2] or ignition aids such as silane gas ([3] p. 173). Various parameters exist 
that describe the intake performance, and an overview was given in [4,5]. Static pressure and temperature ratios are defined as

and

$$
\Pi_{\mathrm{st}}=\frac{p_{c}}{p_{\infty}}
$$

$$
\Theta_{\mathrm{st}}=\frac{T_{c}}{T_{\infty}}
$$

respectively, whereas the subscript $c$ denotes the position at the intake exit or the combustion chamber entrance. Furthermore, the total pressure as well as the total temperature ratios are defined as

and

$$
\Pi_{t}=\frac{p_{t, c}}{p_{t, \infty}}
$$

$$
\Theta_{t}=\frac{T_{t, c}}{T_{t, \infty}}
$$

respectively. The total pressure ratio, which is sometimes referred to as the total pressure recovery, is a measure for the efficiency of the compression, whereas

$$
\Pi_{t}=1
$$

corresponds to isentropic compression. The total temperature ratio in the intake is influenced by the wall boundary condition. For moderate wall temperatures $\left(T_{t, \infty} / T_{w} \approx 2\right)$, the loss in total temperature is relatively low $(\approx 2-5 \%)$.

When combined, numerical and experimental approaches often reveal greater insight into flow phenomena than one by itself. For instance, the Mach number at the cowl closure location, which is an important parameter during intake starting, is frequently extracted from computational fluid dynamics (CFD) simulations [6,7] because measurements would disturb the downstream flow. Furthermore, Riehmer et al. [8] validated numerical tools to cold-flow wind-tunnel experiments; afterward, they performed simulations for reacting flow to yield information on the combustion process.

Moreover, during the combustion process, pressure in the combustor increases [5] due to the heat release, as compared to nonreacting flow. The pressure increase is normally isolated from the intake by the isolator. Nevertheless, the maximum sustainable backpressure of an intakeisolator configuration is an important performance measure. If the heat release in the combustor becomes too large, it can choke the intake. In cold-flow facilities, where combustion is not feasible, the pressure increase is oftentimes imposed by an attached throttle [9,10]. Decreasing the throttle exit area increases blockage and imposes a backpressure, which simulates combustion.

Furthermore, it is important to know if and where regions with locally separated flow occur. These regions influence the location of boundary-layer bleed [10] and fuel injection in the intake [11]. Wall pressure measurements in combination with CFD can reveal more information on the internal intake flow structure.

Finally, it is important to understand the impact of the previously explained intake performance parameters on overall engine performance. A high-fidelity analysis of the intake can be coupled to a one-dimensional analysis of the remaining engine. In this context, one-dimensional parameters have to be extracted from the intake domain. Baurle and Gaffney [12] stressed that the governing equations (mass, momentum, and energy) have to be considered while extracting one-dimensional variables. Otherwise, the results would not be reliable.

In a previous study, we purely focused on the starting behavior of three-dimensional intakes [7]. In this study, we used the same intake configurations, which were all self-starting, but we used wind-tunnel experiments and a numerical simulations subsidiary to determine scramjet intake performance. The influence of the freestream Mach number, cowl geometry, and combustor backpressure on the performance was investigated. The ratio of maximum intake backpressure for unstart to operating pressure was independent of the Mach number and cowl geometry at around 4:1. For a started intake configuration, the backpressure had no influence on wall pressures upstream of the intake throat. A one-dimensional postanalysis led to specific impulse values near 2100 and $2561 \mathrm{~s}$ for the Mach 7 and 6 configurations, respectively.

\section{Methods and Materials}

In this section, the intake model as well as the experimental and numerical setup are described. Furthermore, the investigated conditions and the one-dimensional postprocessing techniques are presented.

\section{A. Scramjet Intake Model}

The three-dimensional scramjet intake model was designed by means of a CFD parameter study by Hohn and Gülhan [13] and Riehmer and Gülhan [14], and a computer-aided design (CAD) image is displayed in Fig. 1. The inclination angle of the main ramp was $8 \mathrm{deg}$, and the sidewalls converged with $7 \mathrm{deg}$ on each side. The sweep angle $\varepsilon$ at the leading edge was $45 \mathrm{deg}$ and continuously increased. The overall contraction ratio (CR) $\mathrm{CR}_{o}$ of the intake was 8.12 , whereas the internal contraction ratio $\mathrm{CR}_{i}$ could be varied between 1.28 and 2.56 due to a movable cowl. The intake throat was located at $0.65 \mathrm{~m}$, and its cross section was $40 \times 65 \mathrm{~mm}^{2}$ with rounded corners $(r=10 \mathrm{~mm})$. Thus, the cross-sectional area was $2514 \mathrm{~mm}^{2}$. V-shaped and straight versions of the intake cowl were manufactured to investigate the influence of the cowl geometry and overboard spillage on intake performance.

On the symmetry plane, along the bottom and top walls, static pressure sensors were installed, and pressures were recorded with Pressure Systems, Inc. (PSI) modules, which sampled with $\approx 3 \mathrm{~Hz}$. Additional pressure sensors were located in the intake cowl. At the intake exit, a rake was positioned that was equipped with alternating pitot as well as static pressure probes [15]. From the static and pitot pressure, the Mach number was calculated, as explained in [7]. Because the length of the pressure ducts was relatively short $(\approx 0.5 \mathrm{~m})$, the time response of the pressure ports was faster than the relatively low sampling rate. The distance from the leading edge to the position of the rake was $0.722 \mathrm{~m}$. The intake throat was followed

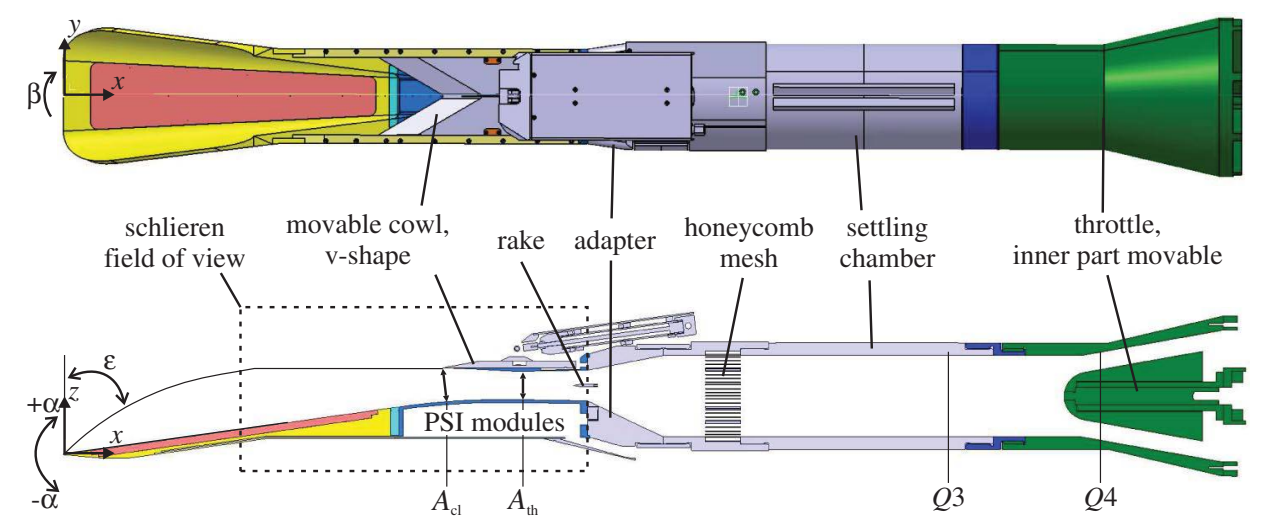

Fig. 1 CAD image of top and cross-sectional view of three-dimensional scramjet intake with attached throttle. 


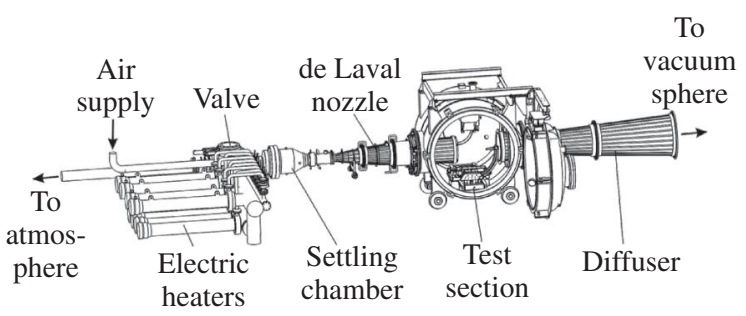

Fig. 2 Schematic setup of the H2K wind tunnel [17] (left) along with flow conditions diagram (right). by a diverging section. The top and bottom walls opened with $1 \mathrm{deg}$ each, whereas the sidewalls remained constant. A schlieren system was installed [16] to record the shock structure at the frontal part of the intake. The schlieren system's field of view is displayed in Fig. 1 .

To the intake model, a settling chamber was attached, which was mounted to the wind-tunnel fixture. At the end of the settling chamber, a conical throttle was attached, and the inner conical part could be moved in streamwise direction. The throttle ratio (TR) was defined as follows:

$$
\mathrm{TR}=\frac{A_{\mathrm{Q} 4, \text { max }}-A_{\mathrm{Q} 4}}{A_{\mathrm{Q} 4, \text { max }}}
$$

Thus, throttle ratios of zero and one corresponded to fully open and closed throttles, respectively. The throttle had two functions. First, an artificial backpressure could be imposed on the intake, and the changes in performance could be investigated. For this purpose, the inner part of the throttle was moved upstream and the smallest cross section at the throttle exit decreased. Consequently, the pressure increased within the settling chamber and at the intake exit. Second, the mass flow through the intake model could be calculated via

$$
\dot{m}_{\text {intake }}=\rho_{\mathrm{Q} 3} v_{\mathrm{Q} 3} A_{\mathrm{Q} 3}
$$

The static pressure and total temperature were measured at Q3 within the settling chamber and, assuming that the flow within the settling chamber was subsonic and accelerated to $M=1$ at the throttle throat (Q4), Eq. (ㅁ) could be transformed to read as follows:

$$
\dot{m}_{\text {intake }}=p_{\mathrm{Q} 3} M_{\mathrm{Q} 3} A_{\mathrm{Q} 3} \sqrt{\frac{\gamma}{R T_{t, \mathrm{Q} 3}}\left(1+\frac{\gamma-1}{2} M_{\mathrm{Q} 3}^{2}\right)}
$$

Note that, for this procedure, the flow within the settling chamber needed to be subsonic, which was satisfied at higher throttling ratios only.

Three intake configurations were investigated. For a Mach number of seven the v-shaped cowl was investigated (M7v); for a Mach number of seven the straight cowl was investigated (M7s); and for a Mach number of six, the v-shaped cowl was investigated (M6v). Because the intake configurations were set to their self-starting limits, the internal contraction ratios were different. For Mach 7, they were 1.91 and 2.11 for the $\mathrm{v}$-shaped and straight cowls, respectively.
For Mach 6, the internal contraction was reduced to 1.71. Further information on the intake starting capability of this specific model can be found in [7].

\section{B. Blowdown Wind Tunnel}

The H2K (Fig. 2), which was used for the experiments, is a cold-flow blowdown wind tunnel [17]. From a high-pressure reservoir, air was led into electric heaters, which heated up the airstream to desired temperatures. During this process, air was released into the atmosphere. Once the desired temperatures were reached, a valve was triggered, and the airstream was released through a de Laval nozzle into the test section before exiting through a diffuser into the vacuum sphere. Depending on the desired conditions, testing times of up to $35 \mathrm{~s}$ could be achieved. There were five de Laval nozzles, all with an exit diameter of $0.6 \mathrm{~m}$, for Mach 5.3, 6, 7, 8.7, and 11.2 conditions. The wind-tunnel conditions that we used are listed in Table $\underline{1}$ and displayed as black bullets $(\bullet)$ in Fig. 2 .

\section{Numerical Modeling}

The conservation of mass, momentum, and energy equations are frequently referred to as the Navier-Stokes equations ([18] p. 57). They can be written in a conservative form as follows:

$$
\begin{gathered}
\frac{\partial \rho}{\partial t}+\nabla \cdot(\rho \boldsymbol{v})=0 \\
\frac{\partial(\rho \boldsymbol{v})}{\partial t}+\nabla \cdot(\rho \boldsymbol{v} \otimes \boldsymbol{v})=-\nabla p+\nabla \cdot \overline{\bar{\tau}} \\
\frac{\partial(\rho E)}{\partial t}+\nabla \cdot(\rho E \boldsymbol{v}+p \boldsymbol{v})=\nabla \cdot(\overline{\bar{\tau}} \cdot \boldsymbol{v}-\boldsymbol{q})
\end{gathered}
$$

where $\otimes$ and $\nabla$ are the outer products of two coordinate vectors and the del operator, respectively. The stress tensor $\overline{\bar{\tau}}$ is symmetrical and contains the three normal components $\tau_{i i} \forall i \in 1,2,3$ and the three shear components $\tau_{i j} \forall i, j \in 1,2,3$. The total energy $E$ is the sum of the internal energy and the kinetic energy:

$$
E=e+\frac{\boldsymbol{v} \cdot \boldsymbol{v}}{2}
$$

Table 1 Wind-tunnel and flight conditions

\begin{tabular}{lcccccc}
\hline \hline & $M$ & $p_{t, \infty}$, bar & $T_{t, \infty}, \mathrm{K}$ & $R e, 1 / \mathrm{m}$ & $p_{\infty}, \mathrm{Pa}$ & $T_{\infty}, \mathrm{K}$ \\
\hline H2K condition & $7 \pm 0.05$ & $10.4 \pm 0.02$ & $700 \pm 20$ & $3.39 \times 10^{6}$ & 251 & 65 \\
& $6 \pm 0.05$ & $8.3 \pm 0.02$ & $700 \pm 20$ & $4.01 \times 10^{6}$ & 523 & 85 \\
Flight condition & 7 & 63.3 & 2430 & $3.39 \times 10^{6}$ & 1528 & 225 \\
& 6 & 32.8 & 1830 & $4.01 \times 10^{6}$ & 2080 & 223 \\
\hline \hline
\end{tabular}


No body forces were considered. For Newtonian fluids, the stress tensor can be can be written as follows [see, e.g., [18] (p. 65)]:

$$
\overline{\bar{\tau}}=2 \mu\left(\frac{1}{2}\left(\nabla \otimes v+(\nabla \otimes v)^{T}\right)-\frac{1}{3}(\nabla \cdot v) \overline{\bar{I}}\right)
$$

The heat flux $\boldsymbol{q}$ is calculated by the following:

$$
\boldsymbol{q}=-\lambda \nabla T
$$

The heat conductivity and viscosity are related by the Prandtl number:

$$
\operatorname{Pr}=\frac{c_{p} \mu}{\lambda}
$$

With the preceding set of equations and corresponding boundary conditions, any flow could be calculated if spatial and time discretizations are sufficiently fine. To reduce the computational effort, Reynolds averaging is used, which divides any fluid variable into a constant and fluctuating value:

$$
\phi=\bar{\phi}+\phi^{\prime}
$$

A detailed description of the averaging technique and the subsequent equations, which are referred to as the Reynolds-averaged Navier-Stokes (RANS) equations, can be found in [19] (p. 10).

In the present work, the RANS equations were solved with the DLR-TAU code [20-22]. DLR-TAU is a finite volume solver, and implicit time stepping was used. Furthermore, the solver was capable of parallelization to simultaneously run one simulation on multiple cores; thus, absolute run times were reduced. For supersonic flow, inviscid terms were discretized with a second-order upwind scheme, whereas second-order central discretization was used for viscous terms. To damp out low-frequency oscillations during time integration faster, the solver could be set to multigrid mode. To model turbulent fluctuations, the two-equation Wilcox $k-\omega$ shear-stress transport turbulence model was used [23]. The boundary layer was assumed to be turbulent from the beginning, which could be considered as conservative for the subsequent propulsion analysis. An isothermal wall boundary condition was used, and inviscid fluxes were reconstructed with a second-order upwind scheme. For the intake simulations, air was treated as a perfect gas with constant $\gamma=1.4$ and $\operatorname{Pr}=0.72$. Viscosity was temperature dependent, and Sutherland's law was used to model the dynamic viscosity via the following:

$$
\mu(T)=\mu_{0}\left(\frac{T}{T_{0}}\right)^{3 / 2} \frac{T_{0}+S u}{T+S u}
$$

while $S u, \mu_{0}$, and $T_{0}$ were the Sutherland constant of $110.4 \mathrm{~K}$, the reference viscosity of $1.716 \times 10^{-5} \mathrm{~kg} / \mathrm{s} / \mathrm{m}$, and the temperature of $273 \mathrm{~K}$, respectively.

For mesh generation, the Centaur (Version 10.5) software package was used. Near viscous wall boundaries, structured elements were used, whereas unstructured elements were used for the remaining domain. A nondimensional wall distance of $y+<1$ was assured, and approximately 35 layers were used. The grids initially consisted of approximately $0.1 \times 10^{6}$ and $0.8 \times 10^{6}$ grid points and elements, respectively. The adaptation tool, implemented in DLR-TAU, was used to refine the grids.

\section{Grid Analysis}

A grid sensitivity analysis was performed by increasing the grid size and monitoring the influence on the solution. The approximate numbers of grid points and elements are summarized in Table 2 . Figure 3 shows the wall pressure along the symmetry plane of the intake. The flow is from left to right, and the intake contour is schematically displayed. Figure $\underline{4}$ shows the average pressure and temperature plotted against the streamwise direction. The grid sensitivity analysis was performed for the $\mathrm{M} 7 \mathrm{v}$ wind-tunnel condition. Wall pressures were practically grid
Table 2 Approximate grid sizes for sensitivity analysis

\begin{tabular}{lcc}
\hline \hline & Elements & Grid points \\
\hline Starting grid & $0.8 \times 10^{6}$ & $0.1 \times 10^{6}$ \\
Grid 1 & $2 \times 10^{6}$ & $0.4 \times 10^{6}$ \\
Grid 2 & $5 \times 10^{6}$ & $1 \times 10^{6}$ \\
Grid 3 & $12 \times 10^{6}$ & $2 \times 10^{6}$ \\
Grid 4 & $29 \times 10^{6}$ & $5 \times 10^{6}$ \\
Grid 5 & $67 \times 10^{6}$ & $12 \times 10^{6}$ \\
\hline \hline
\end{tabular}

independent for grid levels finer than grid 3. Average pressures were practically grid independent, whereas average temperatures fluctuated slightly more. For grid levels finer than grid 4 , the solution seemed to be converged. Thus, the results shown in this work were extracted from grids comparable to grid 4.

\section{E. Wind-Tunnel and Flight Conditions}

During wind-tunnel experiments, the Reynolds number was set according to flight conditions along a constant dynamic pressure trajectory at $q_{\infty}=0.53$ bar. The Mach 6 and Mach 7 nozzles were used; during the experiments, the total temperature was set to $T_{t}=700 \mathrm{~K}$, whereas the Reynolds number was adjusted via the reservoir total pressure. During an experiment, the model heated up. Due to its massive structure, however, the temperature increase of the model was relatively low. After one wind-tunnel run, the surface of the model could still be touched with bare hands. Thus, the maximum temperature increase was assumed to be below $30 \mathrm{~K}$. Therefore, a constant wall temperature of $T_{w}=300 \mathrm{~K}$ was used during CFD simulations of wind-tunnel conditions.

For flight conditions, the total temperature to wall temperature ratio was held approximately constant; therefore, wall temperatures were 1000 and $800 \mathrm{~K}$ for the Mach 7 and 6 cases, respectively. The investigated wind-tunnel and flight conditions are summarized in Table 1.

\section{F. One-Dimensional Postanalysis}

To model the flow through the combustion chamber and nozzle, we extracted average variables while considering the conservation of mass, momentum, and energy equations. Those averages are referred to as stream-thrust averages, and the detailed methodology to extract them was described in [12]. The gas properties (e.g., $\gamma$ and $c_{p}$ ) of the flow through the combustor and nozzle are influenced, for example, by the temperature and composition of the gas. Therefore, the properties vary along the flowpath. Nevertheless, for engine analyses, it is oftentimes more convenient to use constant gas properties that are representative for the individual case ([5] p. 49). In the present analysis, constant $\gamma$ and $c_{p}$ of 1.31 and $1255 \mathrm{~J} / \mathrm{kg} / \mathrm{K}$ were used, respectively. Those values are equal to the ones Smart used in his engine analysis [24]. The models used for the combustor and nozzle are described in the following.

\section{Combustor Model}

The combustion chamber was modeled by a sudden heat release and a subsequent duct with area change and frictional flow. Hydrogen was used as fuel, and its lower heating value (LHV) was $119 \times 10^{6} \mathrm{~J} / \mathrm{kg}$. The changes in properties due to heat release were calculated with the Rayleigh-flow equations, which were valid for inviscid and steady flows and could be found in [25] (p. 299). The general procedure is presented in the following, whereas indices 3 and 4 describe instants before and after the heat release.

1) The change in total temperature/enthalpy due to heat release of the fuel was calculated with a variable equivalence ratio $\varphi$ and constant combustion efficiency of $\eta_{\mathrm{c}}=0.8$ :

$$
h_{t, 4}=h_{t, 3}+\eta_{c} \operatorname{LHV} \frac{\varphi}{m_{\text {stoi }}}
$$

2) With the total temperature, the Mach number was calculated by iteratively solving 


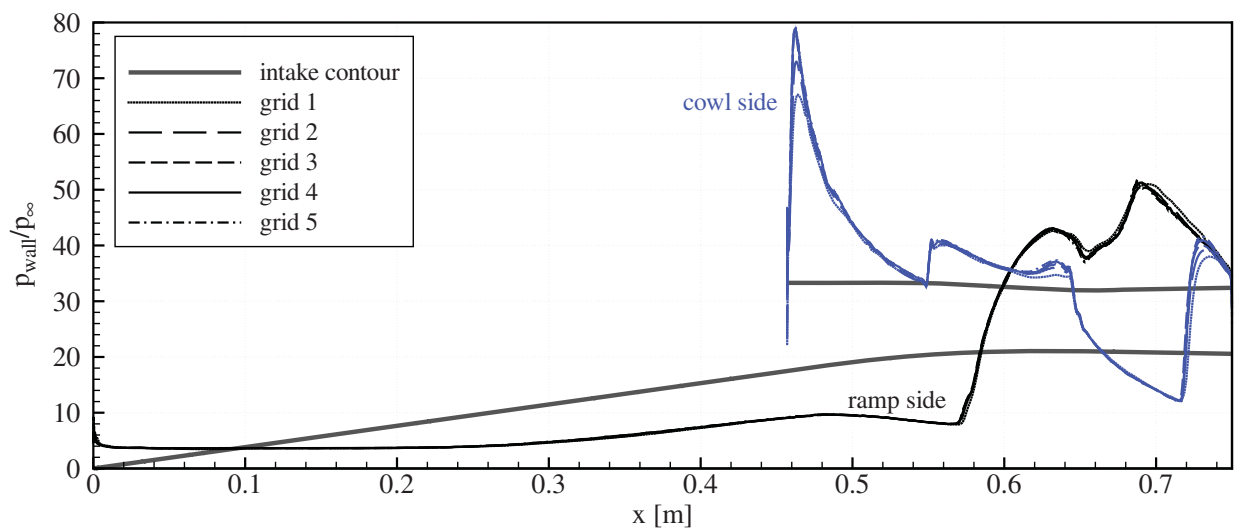

Fig. 3 Influence of grid size on wall pressure.
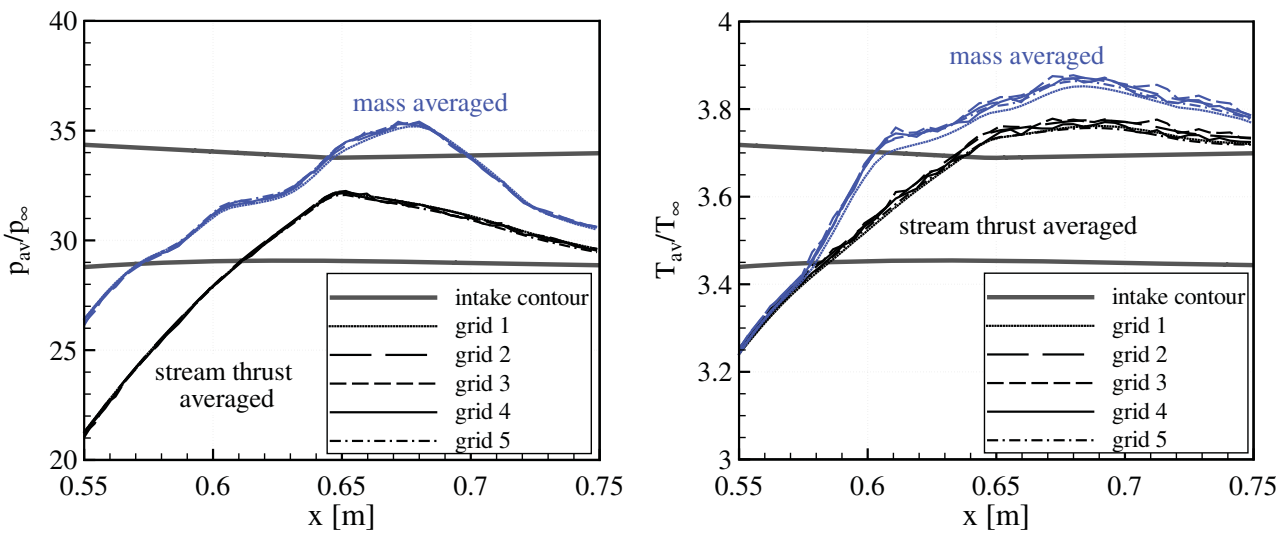

Fig. 4 Influence of grid size on average pressure and temperature in internal portion.

$$
\frac{T_{t, 4}}{T_{t, 3}}=\frac{\left(1+((\gamma-1) / 2) M_{4}^{2}\right) M_{4}^{2}}{\left(1+((\gamma-1) / 2) M_{3}^{2}\right) M_{3}^{2}}\left(\frac{1+\gamma M_{3}^{2}}{1+\gamma M_{4}^{2}}\right)^{2}
$$

for $M_{4}$.

3) Finally, the temperature and pressure were calculated via

$$
T_{4}=T_{t, 4}\left(1+\frac{\gamma-1}{2} M_{4}^{2}\right)^{-1}
$$

and

$$
p_{4}=p_{3} \frac{1+\gamma M_{3}^{2}}{1+\gamma M_{4}^{2}}
$$

The changes in properties in the subsequent duct were calculated for steady, frictional, and adiabatic flows. To calculate the Mach number, the following differential equation was integrated numerically:

$$
\frac{\mathrm{d} M}{M}=\underbrace{-\left(\frac{1+((\gamma-1) / 2) M^{2}}{1-M^{2}}\right) \frac{\mathrm{d} A}{A}}_{\text {influence of area change }}+\underbrace{\left(\frac{1+((\gamma-1) / 2) M^{2}}{1-M^{2}}\right) \frac{\gamma M^{2} 4 c_{f} \mathrm{~d} x}{2} D_{\mathrm{H}}}_{\text {influence of friction }}
$$

The friction coefficient $c_{f}$ was set to 0.002 , and the length of the combustion chamber was $0.4 \mathrm{~m}$. The opening angle of the combustor duct was $1 \mathrm{deg}$. With the Mach number distribution, the temperature and pressure could be calculated via

$$
\frac{\mathrm{d} T}{T}=-\frac{(\gamma-1) M^{2}}{1+((\gamma-1) / 2) M^{2}} \frac{\mathrm{d} M}{M}
$$

and

$$
\frac{\mathrm{d} p}{p}=-\frac{\mathrm{d} A}{A}+0.5 \frac{\mathrm{d} T}{T}-\frac{\mathrm{d} M}{M}
$$

If, during the integration, the Mach number became sonic, the equivalence ratio was reduced by 0.001 to enforce supersonic flow throughout the combustor. Further information on flow with friction and area change can be found in [26] (p. 225).

\section{Nozzle Model}

To model the flow through the nozzle, we used the isentropic flow relations for a given area ratio. The nozzle's area ratio was equal to the intake's overall contraction ratio, thus 8.12 . Positions 4 and 10 describe the nozzle entrance and exit, respectively. Via

$$
\left(\frac{A_{10}}{A_{4}}\right)^{2}=\left(\frac{M_{4}}{M_{10}}\right)^{2}\left(\frac{1+((\gamma-1) / 2) M_{10}^{2}}{1+((\gamma-1) / 2) M_{4}^{2}}\right)^{(\gamma+1) /(\gamma-1)}
$$

the change in Mach number for the given area ratio was calculated and, by assuming inviscid and adiabatic flow, the pressure and temperature could be calculated by solving

$$
p_{4}^{1-\gamma} T_{4}^{\gamma}=p_{10}^{1-\gamma} T_{10}^{\gamma}=\text { const. }
$$

and

$$
T_{4}\left(1+\frac{\gamma-1}{2} M_{4}^{2}\right)=T_{10}\left(1+\frac{\gamma-1}{2} M_{10}^{2}\right)
$$

for $T_{10}$ and $p_{10}$. The contraction ratio of the nozzle was set equal to the intake overall contraction ratio. Further information on isentropic flow through nozzles can be found in [27] (p. 510). 


\section{Results}

In this section, wall pressure measurements, the intake behavior under backpressure, rake measurements, and engine performance calculated with the one-dimensional postanalysis are presented.

\section{A. Wall and Averaged Pressures}

For the Mach 7 case with a v-shaped cowl, on the intake ramp, there was very good agreement between the experimental and numerical wall pressures (Fig. 5). The Mach number contour plot indicated that there was a separation region on the ramp side caused by the reflected cowl shock. Downstream of the separation region, the wall pressure calculated with CFD was slightly displaced from experimental results. We believe that the differences between CFD and the experiments were caused by not modeling the separation region accurately enough with the turbulence model. However, the overall changes were small and, for the most part, CFD results were within the uncertainty of the experimental results. Both Mach 7 cases were quantitatively similar, except for the region underneath the intake cowl. There, the normalized pressure level was at around 40 for the straight cowl configuration (Fig. 6) and lower when compared to the $\mathrm{v}$-shaped cowl geometry (v-cowl) case, which had normalized pressures around 80 . The pressure level observed for the Mach 6 configuration (Fig. 7) was lower, caused by the lower Mach number, and therefore weaker shock system. In Fig. 7, the Mach number contour plot indicated a separation region similar to the Mach 7 case on the ramp side, caused by the reflected cowl shock. Downstream of the separation region, numerical and experimental pressures were slightly displaced in the streamwise direction.

Furthermore, mass-averaged (m-av) and stream-thrust-averaged (str-thr-av) static pressure ratios for $x>0.55 \mathrm{~m}$, extracted from the numerical simulations, are plotted in Figs. 5-7. For all cases, the averaged static pressure ratios had a maximum near $x=0.65 \mathrm{~m}$, where the intake throat was located. Local maximums in massaveraged pressure were slightly downstream of maximums in streamthrust-averaged pressure. In the diverging portion, pressure ratios dropped and mass-averaged pressures approached stream-thrustaveraged levels. Stream-thrust-averaged values were generally lower than mass-averaged values.

In Figs. 5-7, at $x=0.722 \mathrm{~m}$, the average static pressure ratios at the rake, calculated by taking the arithmetic mean of all static pressure ports at the rake, are plotted. The average rake pressure was always lower than the stream-thrust-averaged pressure. This difference between the numerical and experimental average pressures at the rake location is discussed in more detail in Sec. III.C.

\section{B. Backpressure Influence}

To simulate pressure peaks, which can occur in the combustor during the combustion process, a throttle was attached to the

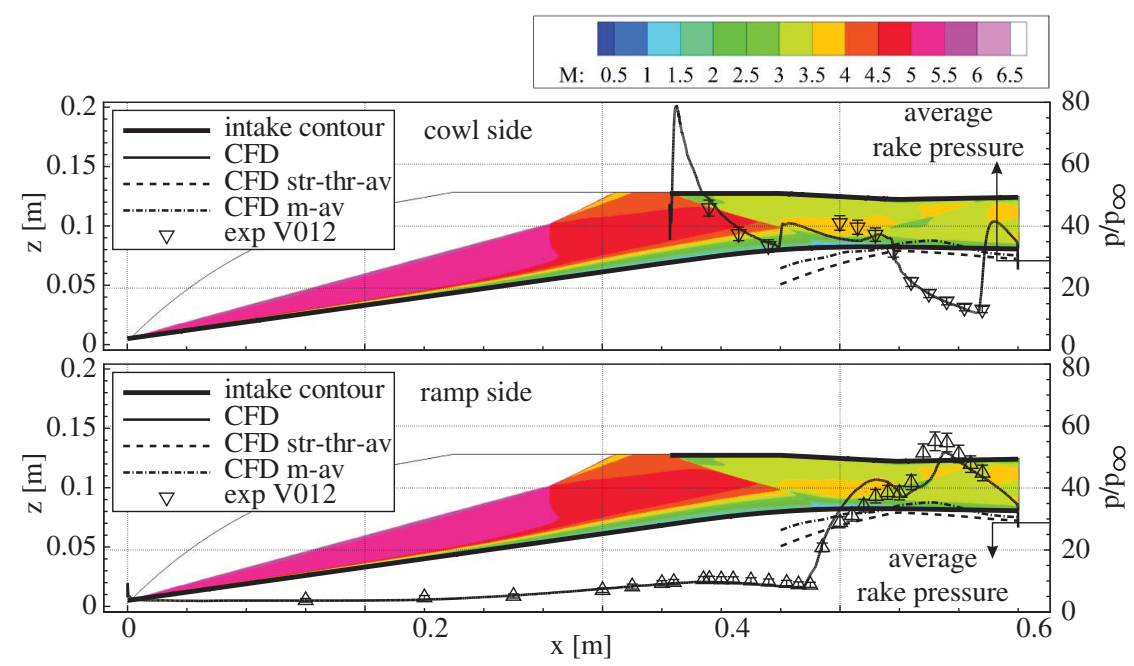

Fig. 5 Comparison of experimental (exp) and numerical (CFD) pressures for $M_{\infty}=7$, v-cowl case; additionally, Mach number contour plots are shown.

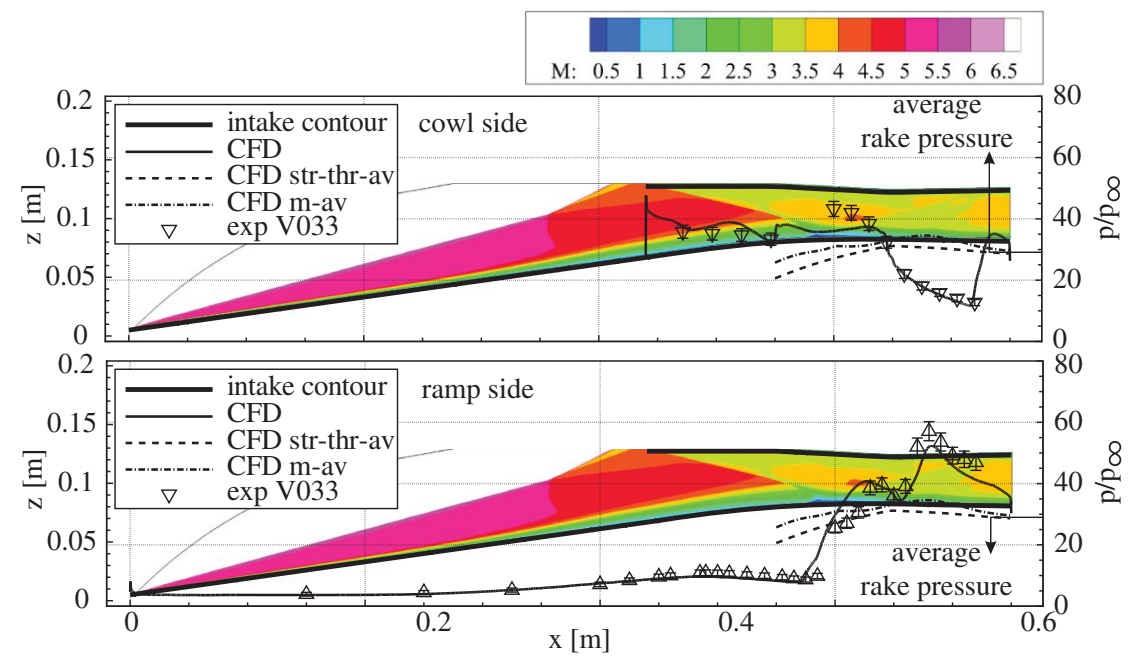

Fig. 6 Comparison of experimental (exp) and numerical (CFD) pressures for $M_{\infty}=7$, s-cowl case; additionally, Mach number contour plots are shown. 


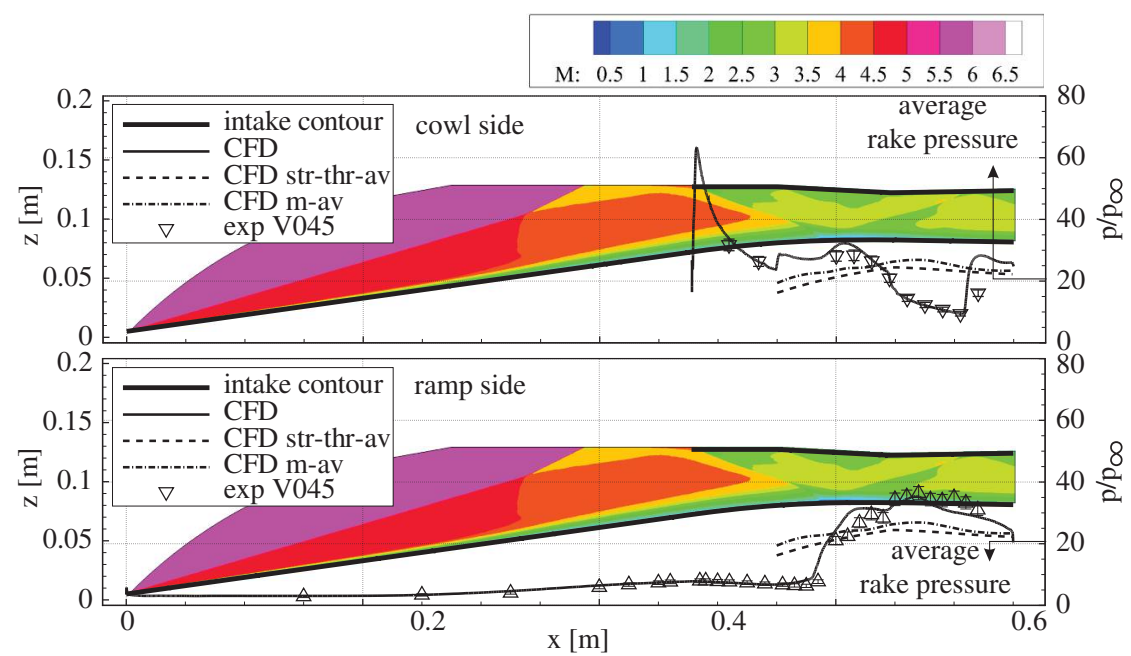

Fig. 7 Comparison of experimental (exp) and numerical (CFD) pressures for $M_{\infty}=6$, v-cowl case; additionally, Mach number contour plots are shown.

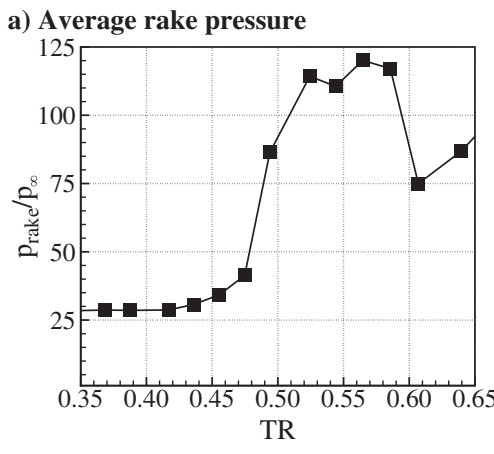

b) Wall pressure

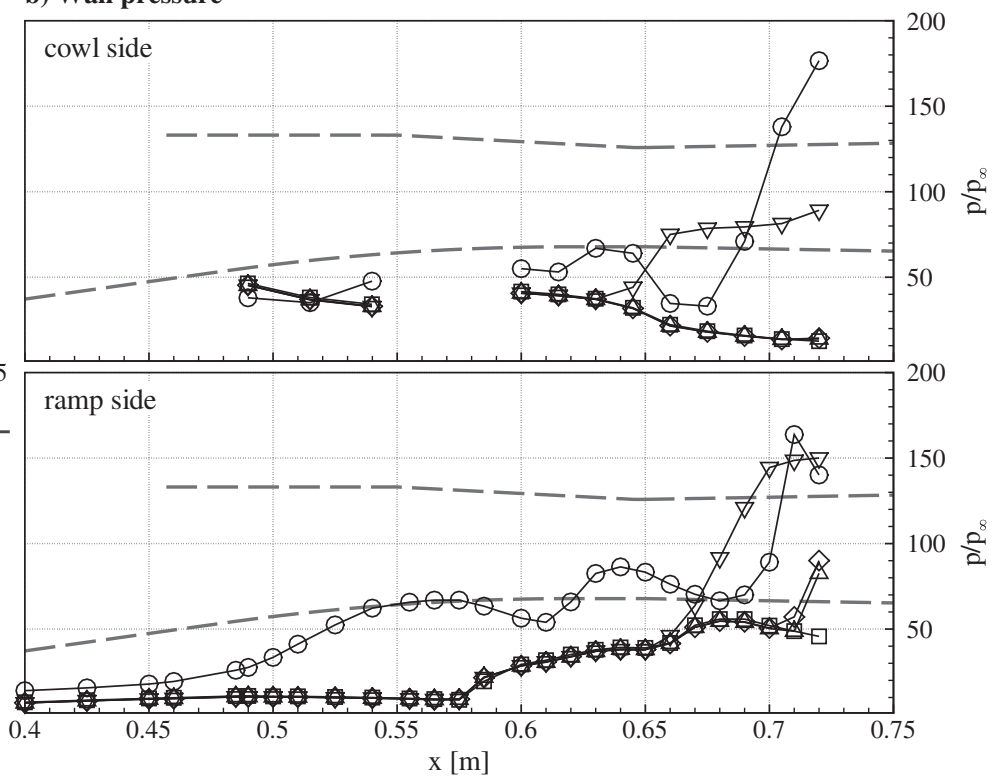

Fig. 8 Average rake pressure and wall pressure under influence of intake throttling for Mach 7, v-cowl configuration.

a) Average rake pressure

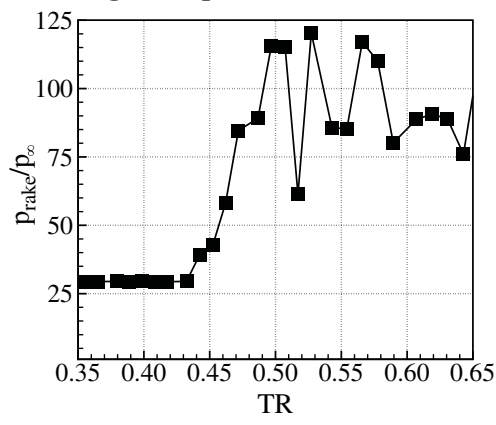

b) Wall pressure

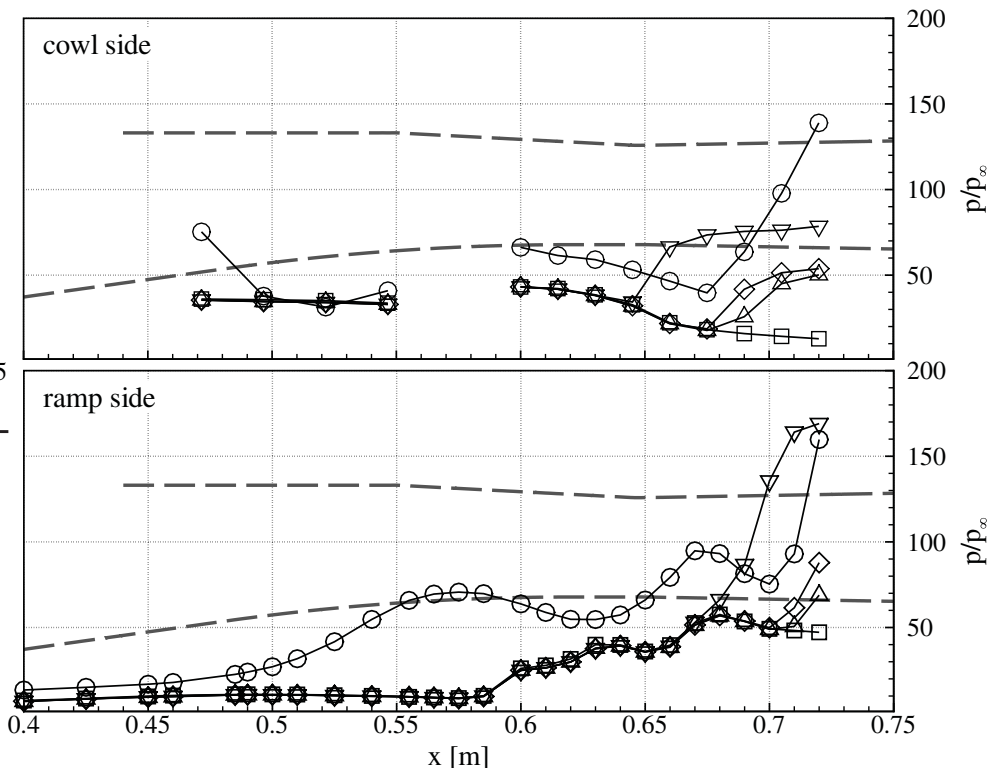

Fig. 9 Average rake pressure and wall pressure under influence of intake throttling for Mach 7, s-cowl configuration. 
intake exit. For the three configurations, the throttle was closed while pressures at the intake wall and rake were measured.

First, the Mach 7 configuration with the v-shaped cowl is discussed. For increasing throttle ratio, the throttle closed; thus, the intake blockage and exit pressure increased (Fig. 8a). The intake operating pressure ratio was at around 28.6, and intake unstart occurred for a pressure ratio near 114 . Thus, the ratio of maximum intake exit pressure to intake operating pressure was $4: 1$. For increasing intake exit pressure, the corresponding wall pressures are plotted in Fig. 8b. The data point near TR $=0.5$ (Fig. 8a), for instance, corresponded to the wall pressure curve with $p_{\text {rake }} / p_{\infty}=86.4$ (Fig. 8b). For low backpressure, the cowl side was unaffected and the backpressure increase was only felt on the ramp side. Further increasing the backpressure led to a pressure increase on the cowl side as well. For a started intake, the flow upstream of the throat was unaffected by backpressure. During intake unstart $\left(p_{\text {rake }} / p_{\infty}=114.3\right)$, the influence of backpressure was felt throughout the intake.
For Mach 7, the straight cowl slightly increased the operating pressure ratio to 29.4 (Fig. 9a). During throttling, the intake unstarted for a pressure ratio near $1 \overline{15}$, which corresponded to four times the operating pressure ratio. Wall pressures rose simultaneously on both sides due to the backpressure increase (Fig. 9b). For a started intake, the flow upstream of the throat was unaffected by backpressure. During intake unstart ( $\left.p_{\text {rake }} / p_{\infty}=115.4\right)$, the influence of backpressure was felt throughout the intake.

When decreasing the Mach number of the v-cowl configuration from seven to six, the normalized pressure generally dropped due to the lower shock strength. The operating intake exit pressure was around 20.9 and, during throttling, increased to a maximum of around 85 when the intake unstarted (Fig. 10a). Thus, the ratio of maximum intake exit pressure to intake operating pressure was once again $\approx 4: 1$. The wall pressure behaved qualitatively similar to the Mach $7 \mathrm{v}$-cowl configuration. For low backpressure, only the ramp side was affected (Fig. 10b). Higher backpressures caused an increase in wall pressure a) Average rake pressure

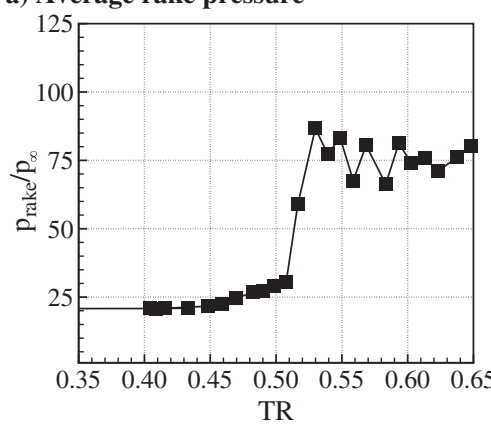

b) Wall pressure

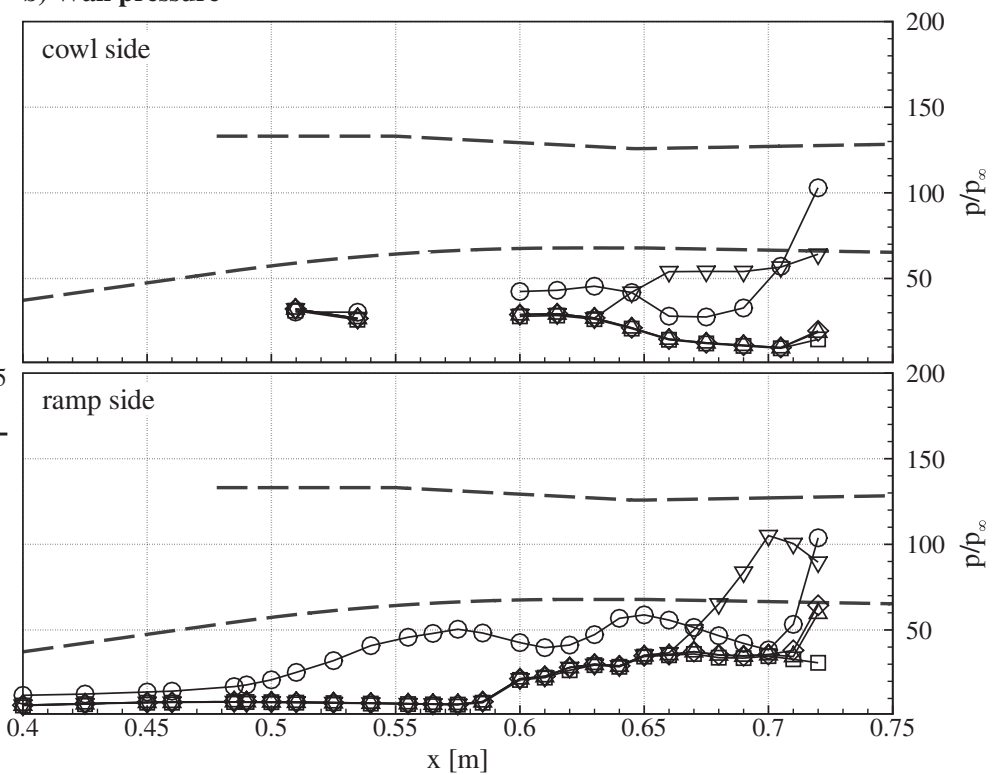

Fig. 10 Average rake pressure and wall pressure under influence of intake throttling for Mach 6, v-cowl configuration.

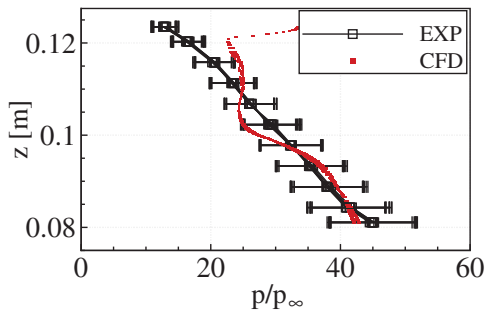

a) Vertical static pressure

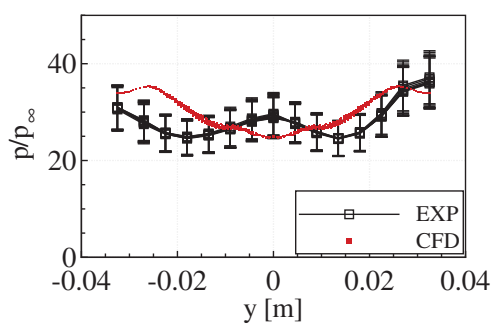

d) Horizontal static pressure

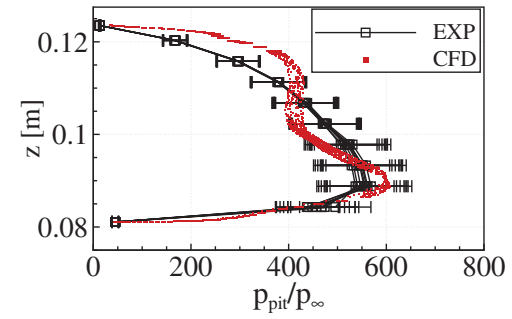

b) Vertical pitot pressure

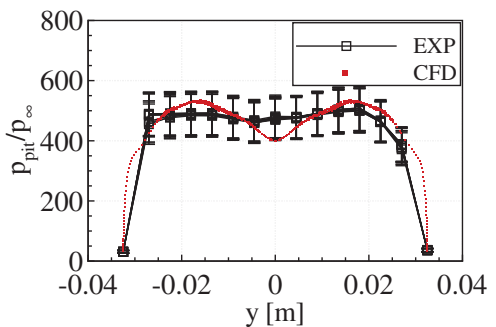

e) Horizontal pitot pressure

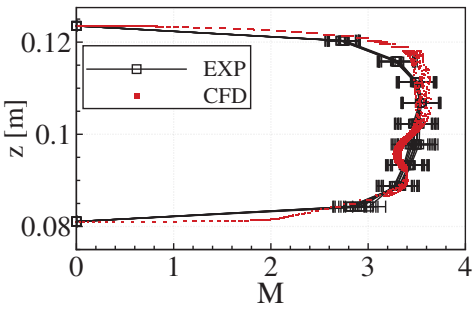

c) Vertical Mach number

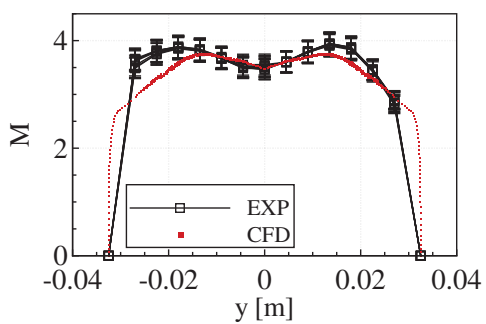

f) Horizontal Mach number

Fig. 11 Static and pitot pressure, as well as Mach number for the Mach 7, v-cowl configuration, at $x=0.722 \mathrm{~m}(\mathrm{EXP}=\operatorname{experiment})$. 
on both sides. For a started intake, the flow upstream of the throat was unaffected by backpressure. During intake unstart $\left(p_{\text {rake }} / p_{\infty}=86.7\right)$, the influence of backpressure was felt throughout the intake.

\section{Rake Measurements}

In Figs. 11-13, measurements along the horizontal and vertical parts of the rake are plotted along with measurement uncertainties as error bars. Multiple measurements are plotted to show fluctuations during a wind-tunnel run. The diameter of a pressure tube was $0.7 \mathrm{~mm}$. Therefore, CFD data were plotted for $z=103 \pm 0.35 \mathrm{~mm}$ (horizontal ports) and $y=0 \pm 0.35 \mathrm{~mm}$ (vertical ports) to illustrate the uncertainty in location. First, the static and pitot pressures are given, which were measured directly. From the static and pitot pressures, the Mach number was calculated, and is plotted as a third variable.

The uncertainty of the instream measurements was larger compared to the wall pressure measurements. This was caused by the generally larger uncertainty of the static and pitot tubes but also by the fact that pressures were partially interpolated from their neighboring values. Overall, the numerical data were within the uncertainty of the experiments. We believe the small displacements between numerical and measured values were caused by the separation region, located upstream of the rake. In the subsequent context, the results are discussed in more detail.

In the Mach 7 case, the static pressure ratio decreased from 40-45 at the bottom to $\approx 15$ at the top. In the numerical results a small highpressure region at the top was observed, which indicated an incoming shock wave. In the horizontal direction, the static pressure measurements of the simulations behaved in an anticyclic manner to the experiments. Although, during the experiments, the pressure in the middle and at the sides was higher and lower, respectively, during the simulations, the opposite behavior was observed. The pitot pressure at the top was generally lower than at the bottom, whereas in the numerical simulations, a plateau was detected at $z \approx 105 \mathrm{~mm}$, which was not present in the measurements. In the horizontal

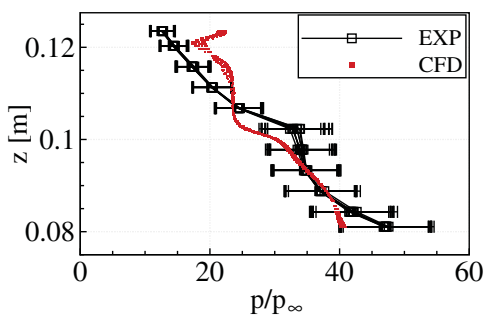

a) Vertical static pressure

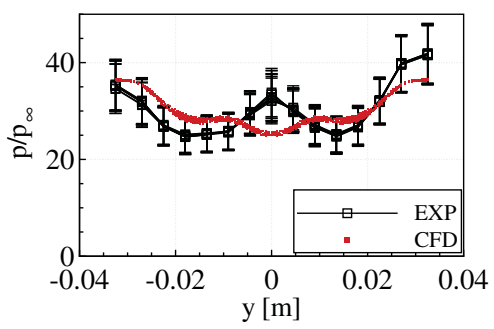

d) Horizontal static pressure

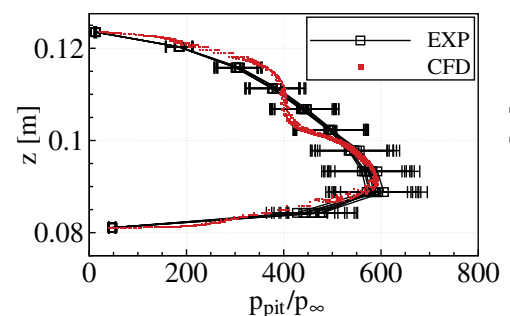

b) Vertical pitot pressure

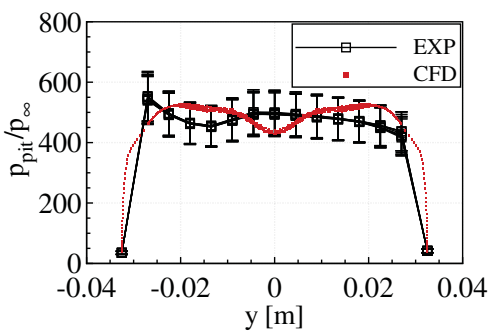

e) Horizontal pitot pressure

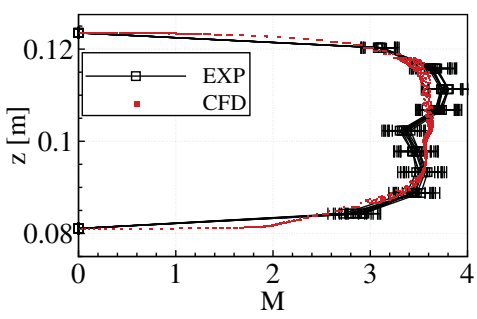

c) Vertical Mach number

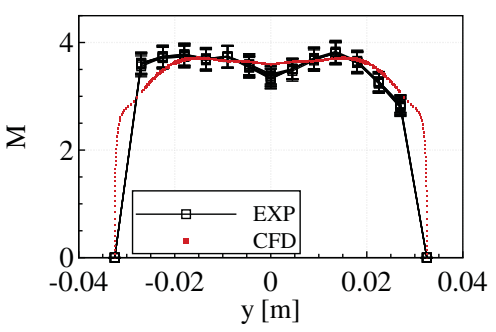

f) Horizontal Mach number

Fig. 12 Static and pitot pressure, as well as Mach number for the Mach 7, s-cowl configuration, at $x=0.722 \mathrm{~m}$.

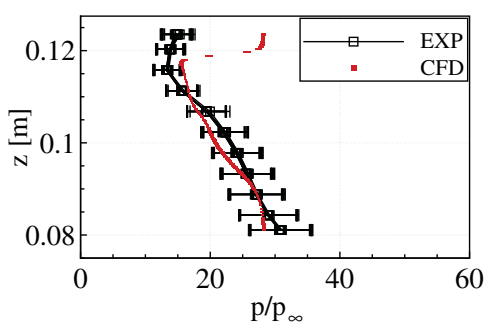

a) Vertical static pressure

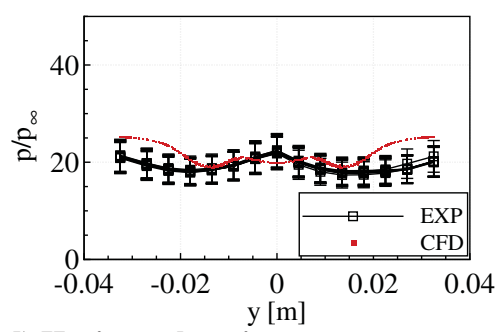

d) Horizontal static pressure

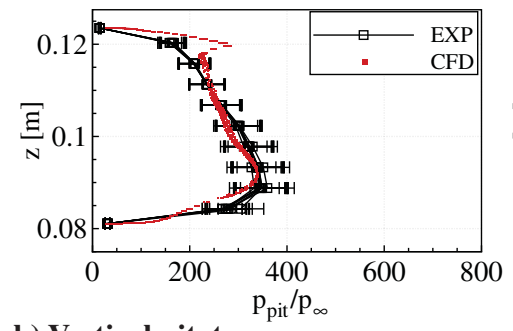

b) Vertical pitot pressure

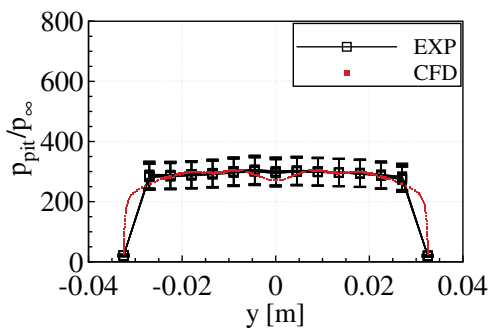

e) Horizontal pitot pressure

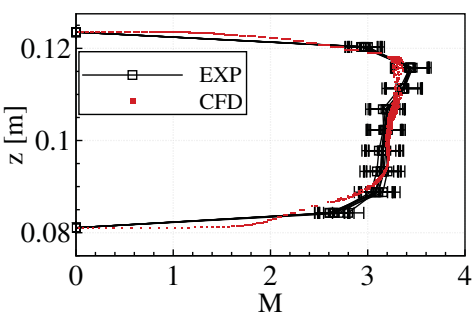

c) Vertical Mach number

Fig. 13 Static and pitot pressure, as well as Mach number for the Mach 6, v-cowl configuration, at $x=0.722 \mathrm{~m}$. 


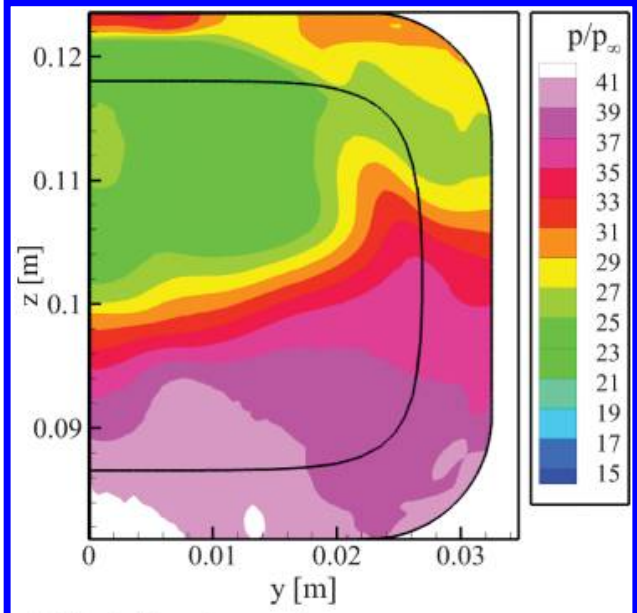

a) Mach 7 and v-cowl case

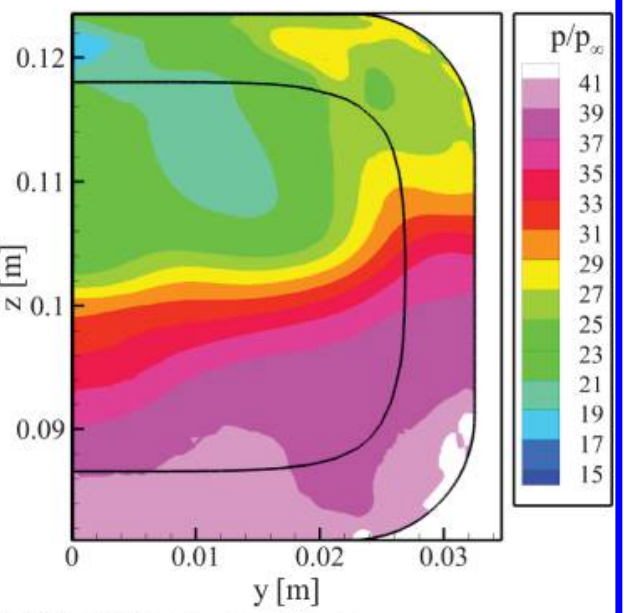

b) Mach 7 and s-cowl case

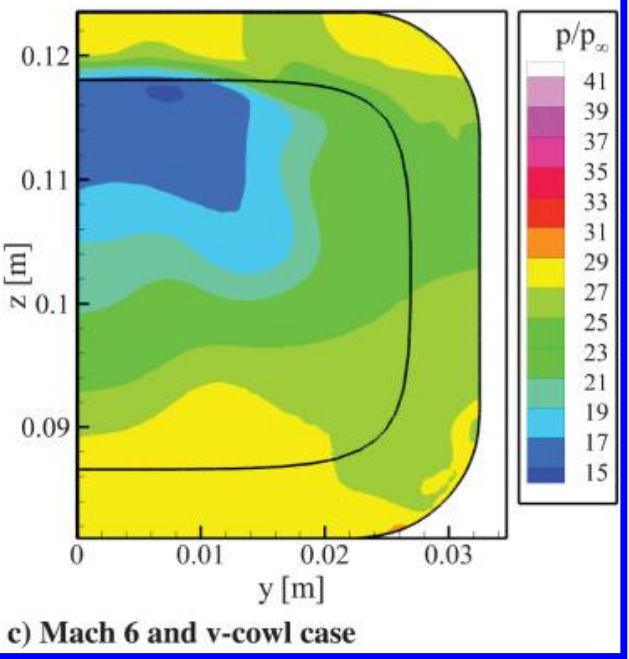

Fig. 14 Cross-sectional planes, extracted from CFD at $x=0.722 \mathrm{~m}$.

direction, the measured and numerically calculated pitot pressures very nicely matched, with the only exception in the very center. There, a static pressure port was located and the respective pitot pressure was interpolated from the neighboring values. The Mach numbers, which were calculated from the pitot and static pressure values, were met very nicely in the vertical direction and only slightly differed at the sides.

Replacing the v-shaped cowl with the straight cowl had little influence on the results. The experimental pressures were slightly less continuous for the straight cowl, which indicated a more heterogeneous flowfield.

In the Mach 6 case, pressures were generally lower, and numerical results matched the experiments better. In CFD results, the highpressure region at the top was more distinct than for the Mach 7 configurations. In experimental results, a tendency toward an increase in pressure at the top was visible.

In Fig. 14, we extracted contour plots from the numerical simulations to provide a better impression of the overall flowfield. Data were extracted at $x=0.722 \mathrm{~m}$, and the pressure was normalized with the respective freestream condition. In the vertical direction, we observed a high pressure at the bottom and a low pressure at the top, which indicated a shock front driving down the isolator. Along the horizontal axis, the pressure level was relatively constant, which matched the experimental results. Only a small shock front was visible at $y=18-20 \mathrm{~mm}$. Furthermore, the three-dimensionality of the flow was clearly visible. The differences between the maximum and minimum static pressure ratios were 21.5 and 25.3 for the v-cowl and straight cowl, respectively. Therefore, the numerical results underline that the flowfield within the v-cowl configuration was slightly more uniform.

\section{One-Dimensional Postanalysis}

To further process the scramjet data, numerical simulations were repeated for flight conditions, and stream-thrust-averaged intake performance parameters were extracted at $x=0.722 \mathrm{~m}$. Because the Mach number, Reynolds number, and total temperature to wall temperature ratio were held constant, changes in the intake performance parameters were below $2 \%$ when comparing simulations of wind-tunnel conditions to flight conditions. Flight conditions and exit conditions are summarized in Tables 1 and 3 , respectively. Furthermore, intake performance parameters based on the stream-thrust-averaged values are given. Finally, we postprocessed the data with the one-dimensional analysis described in Sec. II to calculate overall engine parameters, namely, specific thrust $F_{\text {sp }}$, specific impulse $I_{\text {sp }}$, and overall efficiency $\eta_{\text {oa }}([5]$ p. 116).

First, the maximum equivalence ratio was calculated, which could be used without choking to occur in the combustion chamber, and the level dropped from 0.6 for the Mach 7 configurations to 0.4 for the Mach 6 configuration. This relatively low level could be explained by not considering any heat losses into the combustor walls and enforcing fully supersonic flow in the one-dimensional postanalysis. Replacing the v-cowl with the straight cowl had no effect on specific impulse. The approximately constant specific impulse and thrust levels of $2100 \mathrm{~s}$ and $366(\mathrm{~N} \cdot \mathrm{s}) / \mathrm{kg}$ were observed, respectively. The mass capture ratio of the v-cowl configuration was slightly higher $(0.889)$ than for the straight cowl geometry configuration (0.868).

For the Mach 6 configuration, the maximum $I_{\mathrm{sp}}$ and $F_{\mathrm{sp}}$ were $2561 \mathrm{~s}$ and $297 \mathrm{~N}(\mathrm{~kg} / \mathrm{s})$, respectively. The cowl was located further downstream to account for self-starting; thus, more mass was spilled and the mass capture ratio decreased to 0.778 .

Table 3 Stream-thrust-averaged exit conditions, extracted from CFD for flight conditions, along with intake performance parameters

\begin{tabular}{lccc}
\hline \hline & $M=7, \mathrm{v}-$ cowl & $M=7, \mathrm{~s}-$ cowl & $M=6, \mathrm{v}$-cowl \\
\hline$M_{c}$ & 3.062 & 3.070 & 2.792 \\
$p_{c}, \mathrm{~Pa}$ & 45331 & 44094 & 46898 \\
$T_{c}, \mathrm{~K}$ & 824.31 & 821.81 & 697.08 \\
$\Pi_{\mathrm{st}}$ & 29.667 & 28.857 & 22.547 \\
$\Pi_{t}$ & 0.2890 & 0.2842 & 0.3831 \\
$\eta_{\mathrm{KE}}$ & 0.9565 & 0.9559 & 0.9562 \\
$h_{t, c} / h_{t, \infty}$ & 0.9755 & 0.9756 & 0.9757 \\
$\dot{m}_{c} / \dot{m}_{\infty}$ & 0.8886 & 0.8677 & 0.7777 \\
$\varphi_{\max }$ & 0.605 & 0.607 & 0.403 \\
$F_{\mathrm{sp}}, \mathrm{N} /(\mathrm{kg} / \mathrm{s})$ & 365.82 & 367.16 & 297.32 \\
$I_{\mathrm{sp}}, \mathrm{S}$ & 2099.4 & 2100.1 & 2561.5 \\
$\eta_{\mathrm{oa}}$ & 0.3614 & 0.3615 & 0.3763 \\
\hline \hline
\end{tabular}




\section{Conclusions}

In the current work, the numerical and experimental results of a three-dimensional scramjet intake, operating at its self-starting conditions, were presented. The intake geometry and the experimental setup were explained, and wall pressure plots, as well as static and pitot pressure measurements along the height and width of the intake exit, were discussed for three different configurations. In addition, the intake behavior under backpressure was investigated by imposing blockage with a throttle. Finally, an analytical postanalysis was performed, in which the property change in the combustion chamber was modeled with a Rayleigh flow and flow with friction and area change analysis. The main findings were as follows:

1) When imposing an artificial backpressure, which simulated the pressure increase due to combustion, the maximum sustainable pressure ratios during intake unstart were 115 and 85 for the Mach 7 and 6 cases, respectively; the ratio of maximum pressure to operating pressure was constant at $\approx 4: 1$, independent of the configuration; while the intake was started, the backpressure increase influenced only the portion downstream of the intake throat.

2) The intake exit flow was highly three-dimensional and nonuniform; the straight cowl geometry slightly increased nonuniformity.

3) The analytical postanalysis was a good mean to investigate and directly compare similar intake configurations; the $\mathrm{v}$-shaped and straight cowl configurations had a maximum specific impulse of $2100 \mathrm{~s}$ for Mach 7. For Mach 6, the specific impulse increased to $2561 \mathrm{~s}$.

4) With DLR-TAU, the intake flowfield could be accurately simulated because the numerical simulations were mostly within the experimental uncertainty; deviations were present in the internal portion of the intake only, and they were caused by differences near regions with separated flow.

\section{Acknowledgments}

The present work was funded during Research Training Group 1095/2 (2005-2014). We would like to thank the German Research Foundation (DFG) for the support during that period. Furthermore, we would like to thank Michael Kosbow and Marco Schmors for the operation of the wind tunnel and the technical support.

\section{References}

[1] Riehmer, J. C., "Aerothermodynamische Analysis Eines ScramjetFlugexperiments," Ph.D. Thesis, RWTH Aachen Univ., Aachen, Germany, 2015.

[2] Odam, J., and Paull, A., "Radical Farming in Scramjets," New Results in Numerical and Experimental Fluid Mechanics, Springer, Heidelberg, 2007, pp. 276-283.

-[3] Peebles, C., Road to Mach 10-Lessons Learned from the X-43A Flight Research Program, AIAA Library of Flight, AIAA, Reston, VA, 2008, p. 173.

[4] Billig, F. S., and Wie, D. M. V., "Efficiency Parameters for Inlets Operating at Hypersonic Speeds," International Society of Air Breathing Engines, AIAA Paper 1987-7047, 1987, pp. 118-130.

[5] Heiser, W. H., and Pratt, D. T., Hypersonic Airbreathing Propulsion, AIAA Education Series, AIAA, Washington, D.C., 1994, pp. 49, 116.

-[6] Smart, M. K., "Experimental Testing of a Hypersonic Inlet with Rectangular-to-Elliptical Shape Transition," Journal of Propulsion and Power, Vol. 17, No. 2, 2001, pp. 276-283. doi: $10.2514 / 2.5774$

[7] Flock, A. K., and Gülhan, A., "Experimental Investigation of the Starting Behavior of a Three-Dimensional Scramjet Intake," AIAA Journal, Vol. 53, No. 9, 2015, pp. 2686-2693. doi:10.2514/1.J053786

[8] Riehmer, J. C., Rabadan, E., Guelhan, A., and Weigand, B., "Experimental and Numerical Investigations of a Scramjet Model
Tested in the H2K Blow Down Wind Tunnel at Mach 7," 19th AIAA International Space Planes and Hypersonic Systems and Technologies Conference, AIAA Paper 2014-2933, 2014, pp. 1-14. doi:10.2514/6.2014-2933

[9] Emami, S., Trexler, C. A., Auslender, A. H., and Weidner, J. P., "Experimental Investigation of Inlet-Combustor Isolators for a Dual-Mode Scramjet at a Mach Number of 4," NASA TP 3502, 1995.

[10] Häberle, J., "Untersuchungen zum Externen und Internen Strömungsfeld Eines Scramjet Triebwerkseinlaufs bei Unterschiedlichen Betriebspunkten,” Ph.D. Thesis, Univ. Stuttgart, Stuttgart, Germany, 2009.

[11] Peterson, D. M., Boyce, R. R., and Wheatley, V., "Simulations of Mixing in an Inlet-Fueled Axisymmetric Scramjet," AIAA Journal, Vol. 51, No. 12, 2013, pp. 2823-2832. doi:10.2514/1.J052480

[12] Baurle, R. A., and Gaffney, R. L., "Extraction of One-Dimensional Flow Properties from Multidimensional Data Sets," Journal of Propulsion and Power, Vol. 24, No. 4, 2008, pp. 704-714. doi:10.2514/1.32074

[13] Hohn, O. M., and Gülhan, A., "Analysis of a Three-Dimensional, High Pressure Ratio Scramjet Inlet with Variable Internal Contraction," 18th AIAA/3AF International Space Planes and Hypersonics Systems and Technologies Conference, AIAA Paper 2012-5975, 2012. doi: $10.2514 / 6.2012-5975$

[14] Riehmer, J. C., and Gülhan, A., "Simulation of Combustion by Cold Air Injection in a Generic Scramjet Model in the H2K Blow Down Facility," Proceedings of the 5th European Conference for Aeronautics and Space Sciences, EUCASS Association, Les Ulis Cedex, France, July 2013, http://www.eucass-proceedings.eu/.

[15] Pinckney, S. Z., "An Improved Static Probe Design," AIAA Journal, Vol. 12, No. 4, 1974, pp. 562-564. doi: 10.2514/3.49289

[16] Tropea, C., Yarin, A. L., and Foss, J. F., Handbook of Experimental Fluid Mechanics, Springer, Berlin, 2007, p. 476.

[17] Niezgoda, F.-J., "Der Hyperschallwindkanal H2K des DLR in Köln-Porz,” DLR, Germany Aerospace Center TR 2001-01, Cologne, Germany, 2001.

[18] Anderson, J. D. J., Computational Fluid Dynamics - The Basics with Applications, McGraw-Hill, New York, 1995, p. 57, 65.

[19] Wilcox, D. C., Turbulence Modeling for CFD, DCW Industries, Inc., La Cañada, CA, 1994, p. 10.

[20] Gerhold, T., Galle, M., Friedrich, O., and Evans, J., "Calculation of Complex Three-Dimensional Configurations Employing the DLRTAU-Code," 35th AIAA Aerospace Sciences Meeting and Exhibit, AIAA Paper 1997-0167, 1997. doi: $10.2514 / 6.1997-167$

[21] Mack, A., and Hannemann, V., "Validation of the Unstructured DLR-TAU-Code for Hypersonic Flows," 32nd AIAA Fluid Dynamics Conference and Exhibit, AIAA Paper 2002-3111, 2002. doi:10.2514/6.2002-3111

[22] Schwamborn, D., Gerhold, T., and Heinrich, R., "The DLR TAU-Code: Recent Applications in Research and Industry," Eccomas CFD 2006 Conference, edited by P. Wesseling, E. Oñate, and J. Périaux, TU Delft, Delft, The Netherlands, 2006.

[23] Menter, F. R., Kuntz, M., and Langtry, R., "Ten Years of Industrial Experience with the SST Turbulence Model," Heat and Mass Transfer, edited by K. Hanjalic, Y. Nagano, and M. Tummers, Vol. 4, Begell House, Inc., 2003.

[24] Smart, M. K., "Scramjets," Aeronautical Journal, Vol. 111, No. 1124, 2007, pp. 605-619. doi:10.1017/S0001924000004796

[25] Zucrow, M. J., and Hoffman, J. D., Gas Dynamics Volume I, Wiley, New York, 1976, p. 299.

[26] Oosthuizen, P. H., and Carscallen, W. E., Compressible Fluid Flow, McGraw-Hill, New York, 1997, p. 225.

[27] Anderson, J. D., Fundamentals of Aerodynamics, 4th ed., McGraw-Hill, Boston, MA, 2007, p. 510. 